\title{
The sex matching heuristic in employment decisions
}

\author{
ALFRED G. DAVIS and LOUIS A. PENNER \\ University of South Florida, Tampa, Florida
}

(James J. Jenkins, Sponsor)

\begin{abstract}
The usage of a "sex matching heuristic" in the evaluation of job applicants was investigated. Specifically, we hypothesized that subjects would evaluate applicants more favorably when their gender matched both the sex-role orientation of the job and the predominant gender of future subordinates. Evidence of the first type of sex matching was found only among male subjects who evaluated female applicants. There was an unexpected, but consistent effect for subordinate gender. Applicants who would be supervising predominantly male subordinates were seen as having better job futures than applicants who would be supervising predominantly female subordinates. Both absence of sex matching and the presence of subordinate gender effects were explained by the consideration of when people use stereotypes and the continued existence of stereotypes about the competence of men and women.
\end{abstract}

Since the enactment of Title VII of the Civil Rights Act, considerable research has been generated concerning sexual discrimination in management. Much of the research has focused on the impact of male attitudes toward women in management (Bass, Krusell, \& Alexander, 1971; Bowman, Wortney, \& Greyser, 1965; Garland \& Price, 1977; O'Leary, 1974; Rosen \& Jerdee, 1978; Terborg, Peters, Ilgen, \& Smith, 1977) and the influence of sex-role stereotypes on personnel decisions (Cecil, Paul, \& Olins, 1973; Cohen \& Bunker, 1975; Rosen \& Jerdee, 1974a; Schein, 1978; Terborg, 1977).

In general, past research findings concerning the influence of applicant gender on managerial hiring decisions have been mixed. For example, several studies have shown that males are preferred over equally qualified females for management positions (Dipboye, Fromkin, \& Wiback, 1975; Rosen \& Jerdee, 1974a). Terborg and Ilgen (1975), however, found no differences between the hiring rates of equally qualified male and female applicants, although there was evidence that sexual discrimination influenced later stages of employment. In this study, females were offered lower salaries and assigned more routine tasks than their male counterparts.

A somewhat more promising approach has been to examine how the gender of an individual might interact with other aspects of the job. For example, Cohen and Bunker (1975) investigated the interaction between applicants and the sex-role orientation of the job. Males were evaluated

This article is based on the first author's master's thesis. Portions of this study were presented at the 1984 meeting of the Southern Eastern Psychological Association. The preparation of the final version of this manuscript was supported by research enhancement funds from the College of Social and Behavioral Sciences at the University of South Florida. Reprint requests should be sent to L. A. Penner, Department of Psychology, University of South Florida, Tampa, FL 33620. more favorably than were females when applying for the male-oriented job of personnel technician; females were evaluated more favorably than were males when the job was editorial assistant. Similar results have been obtained by other researchers (Brief \& Wallace, 1976; Feather, 1975; Taynor \& Deaux, 1975).

In another study of the influence that contextual variables might have on hiring decisions, Rose and Andiappan (1978) systematically manipulated the sex of applicants for a managerial position as well as the gender of their potential subordinates. They found no evidence of bias solely on the basis of the applicants' genders. They did find, however, a clear preference for applicants whose genders matched that of the subordinates. This finding led Rose and Andiappan to suggest that the sex-role context of the job, rather than the applicant's sex, may result in discrimination in hiring decisions affecting managerial personnel. This "sex matching heuristic" may cause discrimination against qualified applicants of both genders.

The purpose of the present study was to further explore the effects of sex matching by manipulating the variables identified by Cohen and Bunker (1975) and by Rose and Andiappan (1978) in a single study. Three hypotheses were made: (1) Applicants for a managerial job will be evaluated more favorably when their genders match the sex-role orientation of a job. (2) Applicants for a managerial job will be evaluated more favorably when their genders match that of the majority of their subordinates. (3) These two variables will interact, so that applicants with "matches" on both variables will be evaluated more favorably than other applicants.

\section{METHOD}

\footnotetext{
Subjects

Eighty undergraduates from a large southeastern university participated in the study. Subjects were students in upper-division courses in
} 
business administration, public administration, and psychology. Equal numbers of males and females were used.

\section{Procedure}

Subjects were tested in groups of 15-20 people. Each subject received a copy of a job description and an application form, supposedly completed by the job applicant. After reading this material, subjects answered five questions concerning hiring decisions and suitability of the applicant for the position. In addition, subjects answered eight multiple-choice questions that concerned characteristics of the job, the applicant's sex, and the predominant sex of the applicant's potential subordinates. These questions were used to determine the efficacy of the manipulation of the independent variables.

Job Type. Half of the subjects were presented with a description of a female-oriented position (social work supervisor); the other half were presented with a description of a male-oriented position (accounting supervisor). The employer for both jobs was supposedly a medium-sized city.

These jobs were selected on the basis of three criteria. First, they had been judged by experts as being equal in status and responsibility. Second, they were not so obviously sex typed as to sensitize subjects to the purpose of the study. For example, if jobs such as nursing or mechanical engineering had been used, subjects might have recognized the true purpose of the study and biased their answers so as to avoid the appearance of sex prejudice. And finally, a pilot study conducted with 30 undergraduates disclosed clear differences in the sex typing of the two positions used. Almost $87 \%$ of the subjects in the pilot study thought that the social work position would be held by a woman; $80 \%$ thought that the accounting position would be held by a male.

Subordinate Sex. Each job description contained information on the nature of the work, job duties, minimum qualifications, number of subordinates, salary, and so forth. The two jobs were equivalent across jobtype conditions. Embedded in each job type was a statement about the gender of the applicant's future subordinates. In the predominately male condition, 15 out of the 20 subordinates were male; the numbers were reversed for the predominately female condition.

Applicant Sex. Within each of these four conditions, half the subjects reviewed the application form of a male and half reviewed the application of a female. Applicant forms were identical within each condition, except the person's name varied. Application forms differed slightly across the job-type conditions, so as to make the applicant's work history compatible with the position he/she was applying for. An equal number of males and females were randomly assigned to each of the eight conditions. This procedure yielded a $2 \times 2 \times 2 \times 2$ factorial design with the independent variables being job type, subordinate sex, applicant sex, and subject sex.

Dependent Measures. The subjects assumed the role of the personnel director for a medium-sized city and answered five questions. First, subjects made a yes/no decision on hiring the applicant. Then, the subjects rated, on a 6-point scale, the probability that the applicant would be successful on the job, the probability that the applicant would be successful in working with subordinates, and the likelihood that the applicant would have a long career. Finally, subjects were asked to select, from a list of four choices, the most likely reason for not hiring the applicant. These questions were based on those used by Rose and Andiappan (1978) and Cohen and Bunker (1975).

\section{RESULTS}

\section{Manipulation Check}

The manipulations were correctly perceived by the vast majority of the subjects. Ninety-six percent correctly identified the type of job; $93 \%$ correctly identified the predominant sex of subordinates; and $97 \%$ correctly identified the sex of the applicant. Further analyses failed to disclose any differences in the accuracy of identification as a function of the independent variables.

\section{Modes of Analysis}

Chi-square analyses were used on those questions that yielded categorical or nominal data (Questions 1 and 5); analyses of variance were used in the analyses of continuous data. An LSD test was used for post hoc comparisons. The alpha level for all analyses was set at .05 .

\section{Main Effects}

Job type. Job type had a significant effect on subjects' estimates of the applicants' chances of success in the jobs $[F(1,64)=5.13, p<.05]$. Applicants for the maleoriented managerial job (accountants) were rated as having a significantly greater chance of success than were applicants for the female-oriented job (social workers).

Sex of subordinates. Although the clear majority of the subjects $(91 \%)$ recommended hiring the applicants, they were significantly more likely to do this when the subordinates were predominantly male $(100 \%)$ than when they were predominantly female $(85 \%)\left[\chi^{2}(1)=5.37\right.$, $p<.05]$. Subordinate sex also had a significant effect on ratings of chance for success $[F(1,64)=6.48, p<$ $.01]$ and of likelihood for a long career $[F(1,64)=6.65$, $p<.01]$. Ratings of these were significantly higher when the staff was predominantly male than when it was predominantly female. None of the other main effects was significant.

Interactions. There was a significant job type $\times$ application sex $\times$ subject sex interaction on the question concerned with the likelihood of a long career $[F(1,65)=$ $4.39, p<.05]$. This interaction is presented in Figure 1.

As the figure shows, male and female subjects did not differ in their ratings of the male applicant, but they differed in rating the female applicant. Whereas females did not rate the female applicants for the two types of jobs differently, males estimated that a female applying for the female-oriented job would have a significantly greater likelihood of a long career than would a female applying for the male-oriented job. None of the other interactions was significant.

\section{DISCUSSION}

Only one of the three hypotheses received any support from the data. Male subjects, presented with a female applicant, estimated the likelihood of her having a long career to be significantly greater when the job was female oriented than when it was male oriented. This effect was not obtained for female subjects or male applicants. Similar findings have been obtained by Lillestol (1977) and Muchinsky and Harris (1977). Taken together, these findings suggest that if there is a tendency to match an applicant's gender to the sex-role orientation of the job, this bias may be confined to male judgments about female applicants. Furthermore, in both this study and that of Lillestol, the bias was not manifested in judgments about initial employability, but rather in estimates of how long a female would remain in the job.

There was no evidence that subjects used the sex matching heuristic, proposed by Rose and Andiappan (1978) (i.e., matching applicant's gender with the predominant gender of subordinates), but the gender of subordinates had a consistent effect on the subjects' responses. Subjects were less likely to hire applicants who would be supervising females than applicants who would be supervising males. The subjects 


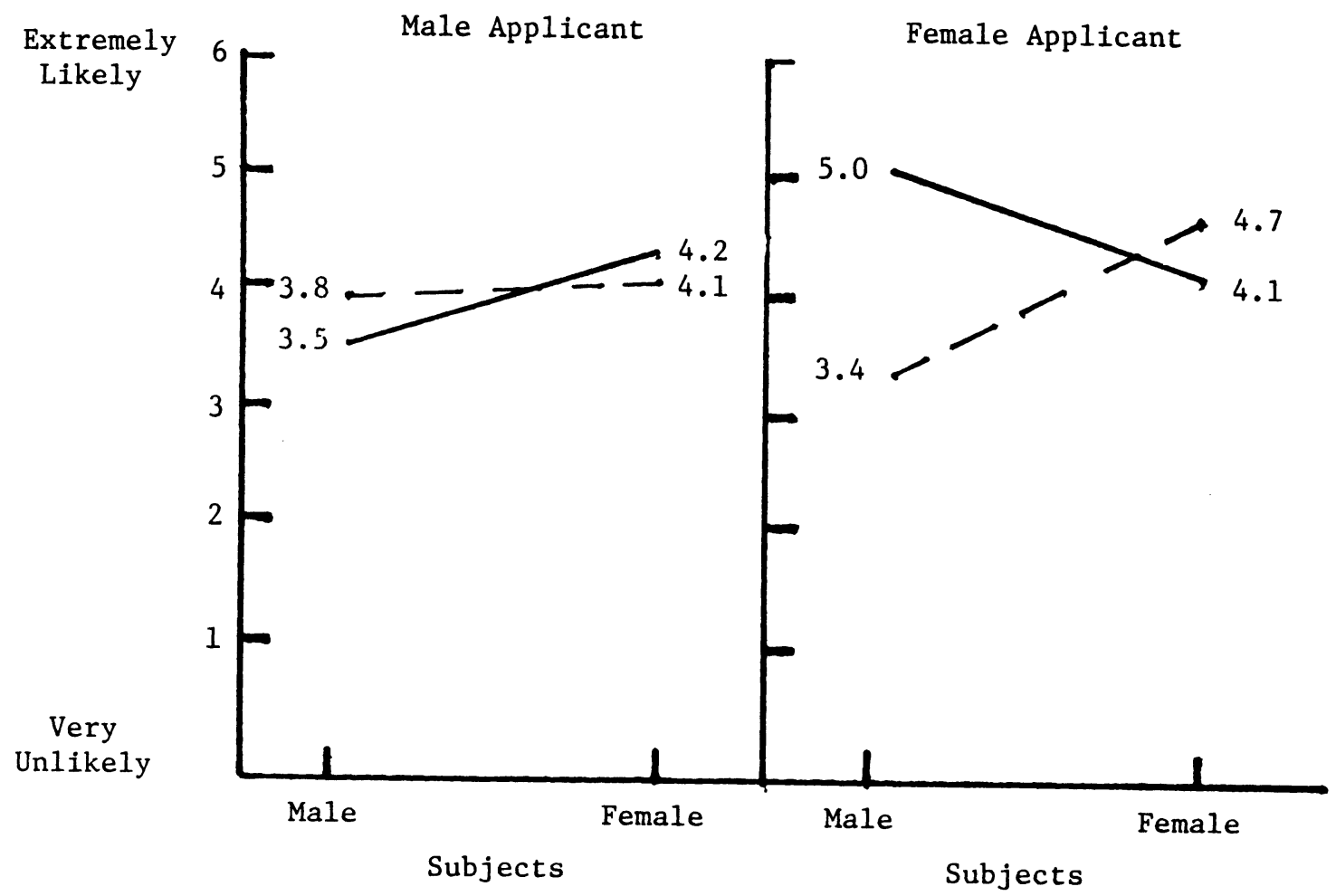

Figure 1. Estimates of the likelihood of a long career as a function of job type, applicant sex, and subject sex.

also predicted that such applicants would be less successful and estimated that their tenure in the job would be shorter.

Both the failure to find a preference for applicants whose gender would match that of their subordinates and the findings of a reliable effect for subordinate gender may be understood by a consideration of when people do and do not base their judgments of a stimulus person on general stereotypes. Typically, stereotypes provide the basis of judgments and evaluations only when there is no other available information about the characteristics of a stimulus person (see, for example, Rokeach \& Mezei, 1966; Stearns, Penner, \& Kimmel, 1980). The job applicants in the present study were not presented in this manner. To the contrary, rather detailed information about their work experience, education, and so forth was provided. Thus, there was no need for the subjects to fall back on stereotypical beliefs (e.g., the sex matching heuristic) in order to make judgments about the suitability of the applicants for a job.

However, in our study, the only information provided about subordinates was their number and gender. It is likely that subjects did base their employment judgments on general stereotypes about men and women. There are a large number of studies that have found that when specific performance data are lacking, females are perceived as less competent and less able to carry out job-related activities than are men (see. e.g. Bass et al., 1971; Bowman et al.. 1965; O'Leary, 1971; Rosen \& Jerdee, 1974a, 1978). Thus, the subjects may have been implying that someone who supervises competent men will be more successful than someone who supervises incompetent women.

Alternatively, the gender of the subordinates may have influenced the subjects' view of the status inherent in their supervisors' positions. Since jobs that are typically held by males are accorded more status than those typically held by females (Eagly \& Steffen, 1984), supervisors of the former are expected to have more status than supervisors of the latter, and they would be expected to have a longer and more successful career in the organization. This explanation of subordinate effects and the previ- ous one are not mutually exclusive. Both are based on the activation of sex-role stereotyping in the absence of detailed information.

The status differential between male- and female-oriented jobs may also explain the significant effect for job type. Subjects estimated that applicants for a male-oriented job would be more successful than applicants for a female-oriented job. Since male-oriented jobs are typically valued more highly than female-oriented jobs, someone who occupied the former would be seen as having a greater chance for success than someone who occupied the latter. These explanations, or course, are tentative and require direct empirical testing of their validity.

In summary, this study provided limited support for the existence of a general sex matching heuristic; it was found only when male subjects evaluated female applicants, and was restricted to the matching of applicant gender with the sex-role orientation of the job. The findings also suggest that, unfortunately, stereotypes about the relative incompetence of men and women are alive and well among members of both sexes. In those situations in which stereotypes are not overridden by actual data, employers may resort to them. The resulting effect may be unfair to both men and women, but the cost incurred by women still appears to be somewhat greater.

\section{REFERENCES}

Bass. B. M., Krusell, J., \& AleXander, R. A. (1971). Male manager's attitudes toward working women. American Behavioral Scientist, 15, 221-236.

Bowman, G. W.. Wortney, N. B., \& Greyser, S. A. (1965). Are women executives really people? Haniard Business Review, 43, 52-67.

Brief, A. P., \& Wallace, M. J. (1976). The impact of employee sex and performance on the allocation of organizational rewards. Journal of Psychology, 92, 25-34.

Cecil, E. H., Paul, R. J., \& Olins, R. A. (1973). Perceived impor- 
tance of selected variables used to evaluate male and female job applicants. Personnel Psychology, 26, 397-404.

COHEN, S. L., \& BUNKer, K. A. (1975). Subtle effects of sex-role stereotypes on recruiter's hiring decisions. Journal of Applied Psychology, 60, 566-572.

Dipboye, R. L., Fromkin, H. L., \& Wiback, K. (1975). Relative importance of applicant sex, attractiveness, and scholastic standing in job applicant resumes. Journal of Applied Psychology, 60, 39-43.

EAGLY, A. H. \& StefFEN, V. S. (1984). Gender stereotypes stem from the distribution of women and men into social roles. Journal of Personality \& Social Psychology, 46, 735-754.

Feather, N. T. (1975). Positive and negative reactions to male and female success and failure in relation to the perceived status and sextyped appropriateness of occupations. Journal of Personality \& Social Psychology, 31, 536-548.

Garland, H., \& Price, K. H. (1977). Attitudes toward women in management and attributions for their success and failure in a managerial position. Journal of Applied Psychology, 62, 29-33.

LILLESTOL, J. B. (1977). Effect of applicant's sex, organizational level of job and sex of personnel manager on evaluations of candidates for managerial positions in retail merchandising. Dissertation Abstracts International, 38(6-A), 3601.

Muchinsky, P. M., \& HaRris, S. L. (1977). The effect of applicant sex and scholastic standing on the evaluation of job applicant resumes in sex typed occupations. Journal of Vocational Behavior, 11, 95-108.

O'LeARY, V. E. (1974). Some attitudinal barriers to occupational aspirations in women. Psychological Bulletin, 81, 809-826.

RoKEACH, M., \& MEZEI, L. (1966). Race and shared belief as factors in social choice. Science, 151, 167-172.
Rose, G. L., \& ANDIAPPAN, P. (1978). Sex effects on managerial hiring decisions. Academy of Management Journal, 21, 104-112.

ROSEN, B., \& JERDEE, T. (1974a). Effects of applicant sex and difficulty of job on evaluations of candidates for managerial positions. Journal of Applied Psychology, 59, 511-512.

ROSEN, B., \& JERDEE, T. (1974b). Influence of sex role stereotypes on personnel decisions. Journal of Applied Psychology, 59, 9-14.

Rosen, B., \& JERDEE, T. (1978). Perceived sex differences in managerially relevant characteristics. Sex Roles, 4, 837-843.

SCHEIN, V. E. (1978). Sex role stereotyping, ability and performance: Prior research and new directions. Personnel Psychology, 31, 259-268.

Stearns, B. C., Penner, L. A., \& Kimmel, E. (1980). Sexism among psychotherapists: A case not yet proven. Journal of Consulting and Clinical Psychology, 48, 546-550.

TAYNOR, J., \& DEAUX, K. (1975). Equity and perceived sex differences: Role behavior as defined by the task, the mode, and the actor. Journal of Personality \& Social Psychology, 32, 381-390.

Terborg, J. R., (1977). Women in management: A research view. Journal of Applied Psychology, 62, 647-664.

Terborg, J. R., \& Ilgen, D. R. (1975). A theoretical approach to sex discrimination in traditionally masculine occupations. Organizational Behavior \& Human Performance, 13, 352-356.

Terborg, J. R., Peters, L. H., Ilgen, D. R., \& Smith, F. (1977). Organizational and personal correlates of attitudes toward women as managers. Academy of Management Journal, 20, 89-100.

(Manucript received for publication September 24, 1985.) 